\title{
Behavior of Auxetic Steel Wire RC Columns Exposed to Elevated Temperature
}

\author{
Rajai Z. Al-Rousan ${ }^{a^{*}}$ (D) \\ ${ }^{a}$ Department of Civil Engineering, Jordan University of Science and Technology, Irbid, Jordan. Email: rzalrousan@just.edu.jo. \\ * Corresponding author
}

https://doi.org/10.1590/1679-78256422

\begin{abstract}
Twenty-four rectangular RC column specimens, constructed at 1/3 scale, were tested under axial loading to investigate the use of ASWM (one, two, three, four, and five layers) exposed to elevated temperatures. Six of the column specimens were subjected to laboratory temperature (control or un-damaged specimens) of $230 \mathrm{C}$. Eighteen of the column specimens were subjected to elevated temperatures (six columns at $250^{\circ} \mathrm{C}$, six columns at $500^{\circ} \mathrm{C}$, and six columns at $750^{\circ} \mathrm{C}$ ) for $2 \mathrm{hr}$. The obtained results clearly showed that each axial load resistance, toughness, and stiffness were all negatively affected by escalated temperature degrees. Also, the confinement effectiveness in terms of the ultimate load was decreased with the increase in concrete compressive strength (un-damaged). The number of ASWM layers significantly influenced the ductility, energy absorption, and ultimate load improvement percentage. The number of the ASWM layers considerably enhanced the ductility up to a certain number of erected layers; however, adding more layers had no apparent effect.
\end{abstract}

\section{Keywords}

Thermal Shock, Structural Strength, Axial Strength, Auxetic Steel Mesh, Column.

\section{Graphical Abstract}
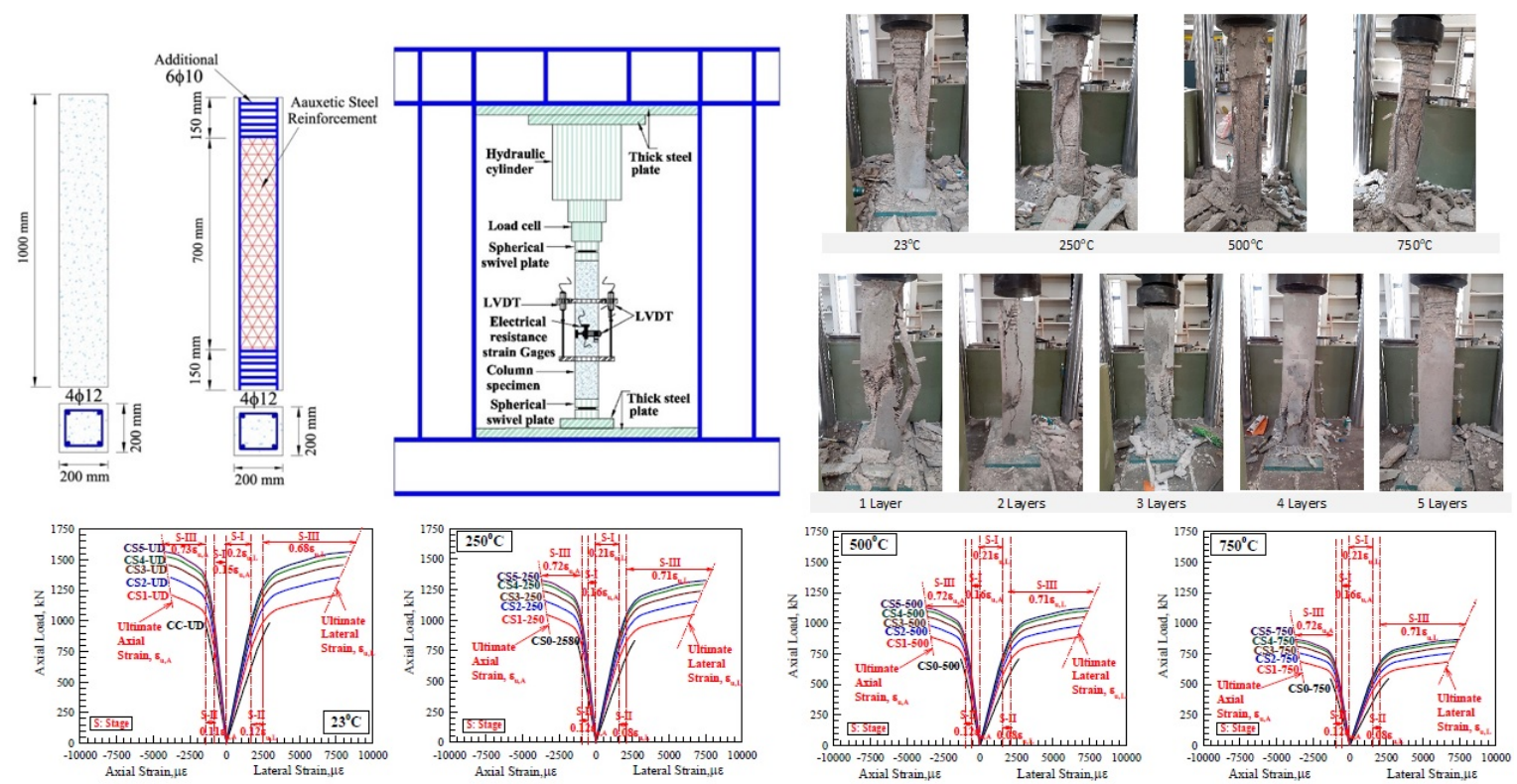

Received January 26, 2021. In revised form January 29, 2021. Accepted January 30, 2021. Available online February 05,2021 https://doi.org/10.1590/1679-78256422

(c) Latin American Journal of Solids and Structures. ISSN 1679-7825. Copyright @ 2021. This is an Open Access article distributed under the terms of the Creative Commons Attribution License, which permits unrestricted use, distribution, and reproduction in any medium, provided the original work is properly cited. 


\section{INTRODUCTION}

Columns in concrete structures are usually designated to convey the loads developed on the structure's foundations. They are also built to withstand extra lateral forces in seismic areas or very tall structures (Ozcan et al. (2008)). As a result, columns must be designed with a significant safety margin, more than any other structural members, to avoid crushing of concrete and/or lateral buckling failure (Al-Rousan (2020), Al-Rousan and Issa (2018), Issa et al. (2009), Al-Rousan and Barfed (2019), Abdalla et al. (2019)). $\mathrm{RC}$ structures are sometimes subjected to deficiency due to one or more: physical and/or chemical changes, electrochemical effects, or fire attacks (Al-Rousan and AL-Tahat (2020), Thipprasert et al. (2019), Bolukbas and Mete (2020), Yhya Laseima et al. (2020), Beydokhti and Shariatmadar (2016). With the development of sophisticated quality control programs to measure quality and design features of structures, failure of concrete columns is diminishing significantly. Fire is the biggest threat to buildings, including multistory hotels, workplaces, and restaurants. Concrete, when subjected to very high temperatures, encounters a degradation in its mechanical characteristics, such as stability, elasticity modulus, flexural strength, and compressive capacity (Arioz (2007), Netinger et al. (2011)). in addition, it is subjected to an alteration, physically and chemically as shown in Table 1.

Table 1 Impact of Temperature on concrete proporties

\begin{tabular}{|c|c|c|}
\hline Temperture $(\mathrm{T}),{ }^{\circ} \mathrm{C}$ & Researcher & Results \\
\hline $\mathrm{T}>110$ & Khoury et al. (2002) & $\begin{array}{l}\text { The calcium silicate hydrate }(\mathrm{CSH}) \text { releases water from its molecules, leading to a } \\
\text { state of hydration (Khoury et al. (2002)). }\end{array}$ \\
\hline $250>T>200$ & $\begin{array}{l}\text { Georgali and Tsakiridis } \\
\qquad(2005)\end{array}$ & Concrete's compressive strength starts to deteriorate \\
\hline $\mathrm{T}=300$ & $\begin{array}{l}\text { Georgali and Tsakiridis } \\
\qquad(2005)\end{array}$ & Concrete loses $15-40 \%$ of its optimal compressive strength \\
\hline $\mathrm{T}>300$ & Hertz (2005) & $\begin{array}{c}\text { Internal stresses are developed, causing the aggregates to thermally expand and } \\
\text { inducing cracks }\end{array}$ \\
\hline $\mathrm{T}=530$ & $\begin{array}{c}\text { Janotka and } \\
\text { Nurnbergerova (2005), } \\
\text { Georgali and Tsakiridis } \\
\text { (2005) }\end{array}$ & $\begin{array}{l}\text { The concrete Shrinks because of the cement paste's degradation due to the } \\
\text { calcium hydroxide's dissociation }\end{array}$ \\
\hline $\mathrm{T}>500$ & Luccioni et al. (2003) & Concrete encounters permanent changes \\
\hline $\mathrm{T}=550$ & $\begin{array}{l}\text { Georgali and Tsakiridis } \\
\qquad(2005)\end{array}$ & Compressive strength goes down by $55-70 \%$ \\
\hline $\mathrm{T}=800$ & Luccioni et al. (2003) & Concrete gets crumbled \\
\hline $\mathrm{T}>1200$ & Hertz (2005) & $\begin{array}{l}\text { The other cement paste's minerals get glassed which cause drastic micro } \\
\text { variations in concrete, leading it to collapse }\end{array}$ \\
\hline
\end{tabular}

On the other side, hot-rolled steel reinforcement bars maintain their yield strength when exposed to temperatures less than $425^{\circ} \mathrm{C}$. In contrast, the strength of the cold-drawn type of steel reinforcing bars weakens at almost $260^{\circ} \mathrm{C}$ (Neves et al. (1996)). Neves et al. (1996) have indicated that temperatures up to $600^{\circ} \mathrm{C}$ affect, to a limited extent, the residual strength of the hot-rolled type of steel bars when they are cooled down by air. Yet, this residual strength reduces by $30 \%$ at temperatures of $600-900^{\circ} \mathrm{C}$. Also, it has been observed that steel bars encounter a considerable degradation in their bond strength at temperatures beyond $200^{\circ} \mathrm{C}$ (Chiang and Tsai (2003)). Concrete is favored for its remarkable resistance to fire. This distinguishing feature is due to the significant differences in temperatures within the heated concrete element, resulting in a low thermal diffusivity. Concrete elements' thickness governs the core's time to reach the temperature of the heated surface. So, when exposed to a fire attack, the RC element's integrity is solely threatened when the temperature of the concrete and the steel reinforcement gets beyond critical levels (Fletcher et al. (2007)).

Well-designed RC structures are amazingly fire-resistant. That is because concrete is low-conductive to heat and incombustible. However, this is true up to an extent. When temperatures become incredibly high, RC structures' sustainability and safety are endangered. That is because extremely high temperatures degrade the RC element's stiffness and axial resistance. There are many factors determining how severe an RC element is heat-damaged, such as the structure's geometrical prosperities, the construction materials, intensity of load, the highest temperature obtained during a fire attack, and time of exposure heat, and the heat distribution in the burned element. RC columns are seriously harmed when exposed to elevated temperatures for a long time. They may buckle or fall; due to the development of extra stresses resulted from the significant temperature gradient between the surface and the core producing expansive forces. Hence, heat-damaged columns buckle due to service rather than ultimate loads. It is well-stipulated that repairing, with reasonable costs, a heat-damaged RC structure is more economical than 
knocking it down, as long this structure is repairable. The main aim of improving heat-damaged RC columns is to restore their load-bearing capacity as a step towards the rehabilitation of the whole structure. Thus, to ensure a cost-effective and well-done rehabilitation process, reliable and less-costly repair methods and materials must be availed. Classical column-repair methods include steel plates (Priestley et al. (1994), Ramirez et al. (1997), Xiao and Wu (2003)), steel cage (Adam et al. (2009), Garzon-Roca and Adam (2011), Sezen and Miller (2011)), and steel strips (Frangou et al. (1995), Gimenez et al. (2009), Badalamenti et al. (2010), Moghaddam et al. (2010)).

Those techniques have been usually complained of as demanding, destructive, ineffective, and sometimes expensive and incurring additional weight. Recently, auxetic steel wire mesh (ASWM) has been used on a large scale to repair various structures (Iyappan and Elango (2017), Parvin and Wang (2005), Lambert-Aikhionbare and Tabsh (2001), Yang and Ashour (2007), Yang et al. (2009), Yang (2012), Sim and Yang (2009). This is because the ASWM confinement method has been increasingly used to better strengthen the already-standing RC columns because they are less costly than CFRP. ASWM is an effective and economical retrofitting material to improve the column's ductility because it is: cheap, obtainable, and practical. Besides.

The above literature review indicates a lack of knowledge on ASWM confinement of rectangular RC columns that have been damaged by elevated temperature. Hence, the present study explores the potential of using ASWM as internal strengthening in internally strengthen heat-damaged $\mathrm{RC}$ rectangular columns to restore their compressive mechanical performance to its original level. ASWM wrapping effectiveness, number of ASWM layers (one, two, three, four, and five layers), and the elevated temperature $\left(23^{\circ} \mathrm{C}, 250^{\circ} \mathrm{C}, 500^{\circ} \mathrm{C}\right.$, and $\left.750^{\circ} \mathrm{C}\right)$ in the restoration of the heat-damaged columns' stiffness and axial strength experimented.

Table 2 Tested results of confined columns with ASWM

\begin{tabular}{|c|c|c|c|c|c|c|c|}
\hline $\begin{array}{l}\text { Group } \\
\text { Number }\end{array}$ & $\begin{array}{c}\text { Number of ASWM } \\
\text { layers }\end{array}$ & $\begin{array}{c}\text { Column } \\
\text { Designation }\end{array}$ & Temperature, ${ }^{\circ} \mathrm{C}$ & $\Delta \mathrm{u}, \mathrm{mm}$ & $\mathrm{Pu}, \mathrm{kN}$ & $\mathrm{K}_{\mathrm{E}}, \mathrm{kN} / \mathrm{mm}$ & $\mathrm{EA}, \mathrm{kN} \cdot \mathrm{mm}$ \\
\hline \multirow[t]{6}{*}{1} & 0 & CLO-23 & 23 & 4.1 & 984 & 246 & 2230 \\
\hline & 1 & CL1-23 & & 10.6 & 1210 & 324 & 10048 \\
\hline & 2 & $C L 2-23$ & & 11.3 & 1354 & 362 & 12265 \\
\hline & 3 & CL3-23 & & 12.2 & 1457 & 390 & 14371 \\
\hline & 4 & CL4-23 & & 12.7 & 1525 & 408 & 15907 \\
\hline & 5 & CL5-23 & & 13.4 & 1565 & 419 & 17265 \\
\hline \multirow[t]{6}{*}{2} & 0 & CLO-250 & 250 & 4.1 & 864 & 215 & 1877 \\
\hline & 1 & CL1-250 & & 10.4 & 1062 & 279 & 8559 \\
\hline & 2 & CL2-250 & & 10.8 & 1179 & 313 & 10050 \\
\hline & 3 & CL3-250 & & 11.2 & 1267 & 336 & 11279 \\
\hline & 4 & CL4-250 & & 11.8 & 1333 & 352 & 12545 \\
\hline & 5 & CL5-250 & & 12.5 & 1388 & 361 & 13820 \\
\hline \multirow[t]{6}{*}{3} & 0 & CLO-500 & 500 & 3.9 & 727 & 187 & 1457 \\
\hline & 1 & CL1-500 & & 10.2 & 905 & 236 & 7007 \\
\hline & 2 & $C L 2-500$ & & 10.5 & 1006 & 264 & 8160 \\
\hline & 3 & CL3-500 & & 10.9 & 1076 & 284 & 9178 \\
\hline & 4 & CL4-500 & & 11.1 & 1126 & 298 & 9903 \\
\hline & 5 & CL5-500 & & 11.8 & 1171 & 306 & 10950 \\
\hline \multirow[t]{6}{*}{4} & 0 & CL0-750 & 750 & 3.6 & 565 & 155 & 1032 \\
\hline & 1 & CL1-750 & & 9.2 & 700 & 186 & 4829 \\
\hline & 2 & CL2-750 & & 9.4 & 782 & 208 & 5561 \\
\hline & 3 & CL3-750 & & 9.8 & 842 & 224 & 6320 \\
\hline & 4 & CL4-750 & & 10.2 & 882 & 234 & 6930 \\
\hline & 5 & CL5-750 & & 10.5 & 910 & 240 & 7402 \\
\hline
\end{tabular}

Note: C: Column, L: Number of ASWM layers, Pu: Ultimate load, $\Delta \mathrm{u}$ : Ultimate Displacement, KE: Elastic Stiffness, EA: Energy Absorption

\section{DESCRIPTION OF EXPERIMENTAL PROGRAM}

\subsection{Test Specimens}

Twenty-four rectangular RC column specimens were constructed and experimented, till failure, under axial loading (Table 2 and Figure 1). The dimensions of the specimens were: $1000 \mathrm{~mm}$ long and a cross-section of $200 \times 200 \mathrm{~mm}$. The 
specimens were reinforced, in a longitudinal direction, with $4 \varphi 12 \mathrm{~mm}$ steel bars $(\rho=1.13 \%$ and yielding stress of $420 \mathrm{MPa})$, with no lateral reinforcement. Avoiding extensive stresses and consequent early failure, $6 \varphi 10$ ties were erected, distanced $150 \mathrm{~mm}$ away from each end to strengthen the columns' ends. The specimens were confined with high-tensiledeformed ASWM. The steel wire mesh's physical and mechanical properties as tested in the structural laboratory are shown in Table 3, respectively. Figure 2 shows a stress-strain diagram of concrete, steel reinforcement, and steel wire mesh. Figure 1 illustrates the specimens: details of reinforcement, cross-sections, and ASWM confinement configurations, while Table 2 shows the specimens' designations and test results.

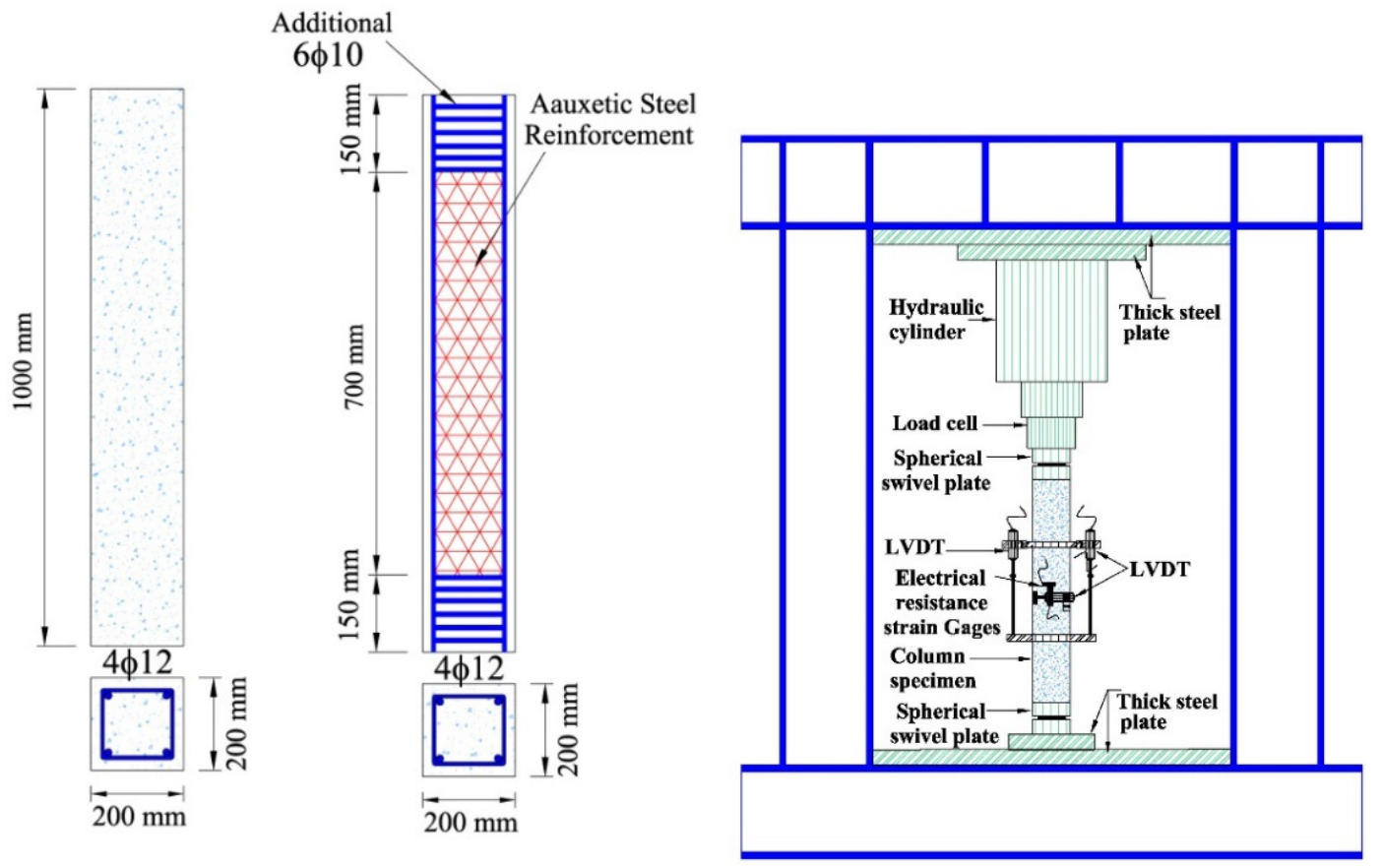

Figure 1 Setup and reinforcement details of the columns

Table 3 Physical and mechanical properties of steel wire mesh

\begin{tabular}{cc}
\hline Component & Descrption \\
\hline Size of each grid of the mesh & $28 \mathrm{~mm} \times 12 \mathrm{~mm}$ \\
The diameter of the wire & $0.119 \mathrm{~mm}$ \\
Tensile Strength & $450 \mathrm{~N} / \mathrm{mm}^{2}$ \\
Ultimate Strength & $697 \mathrm{~N} / \mathrm{mm}^{2}$ \\
\hline
\end{tabular}

\subsection{Concrete Mixture}

The components of the concrete mix consisted of designed in the following by-weigh proportions: water, Ordinary Type I Portland cement, coarse aggregates of crushed limestone (sized $12.5 \mathrm{~mm}$ max., an absorption percentage of $2.3 \%$, and a specific gravity of 2.62), fine aggregates (absorption percentage of $1.9 \%$, fineness modulus of 2.69 , and a specific gravity of 2.65), in the by-weight ratios of 0.59: 1.00: 2.98: 2.62, respectively. A super-plasticizer was added, in a percentage of cement's weight, to the mixture in order for the concrete to be better in quality and avail a slump with a size of $50 \mathrm{~mm}$.

A tilting drum mixer (capacity of $0.15 \mathrm{~m}^{3}$ ) was employed to cast the RC column specimens (Figure 3 ). The process consisted of the following steps: i) the internal surface of the drum mixer was soaked; ii) upon keeping the drum turning, the total amount of the coarse aggregates was put in the mixer along with a part of with the used water (Figure 3); iii) the cement, fine aggregates, and water were gradually put in the mixer; iv) the remained amount of the used water and the super-plasticizer were added to the mixture; and v) the mixture had been mixed for five minutes before it was poured into molds made of wood (dimensioned, internally, $200 \times 200 \times 1000 \mathrm{~mm}$ ), and compacted using an electrical vibrator (Figure 3). After being casted for twenty-four hours, all of the specimens were removed out of the molds; then, they were cured for 24 days in a tank filled with lime-saturated water (Figure 3). 

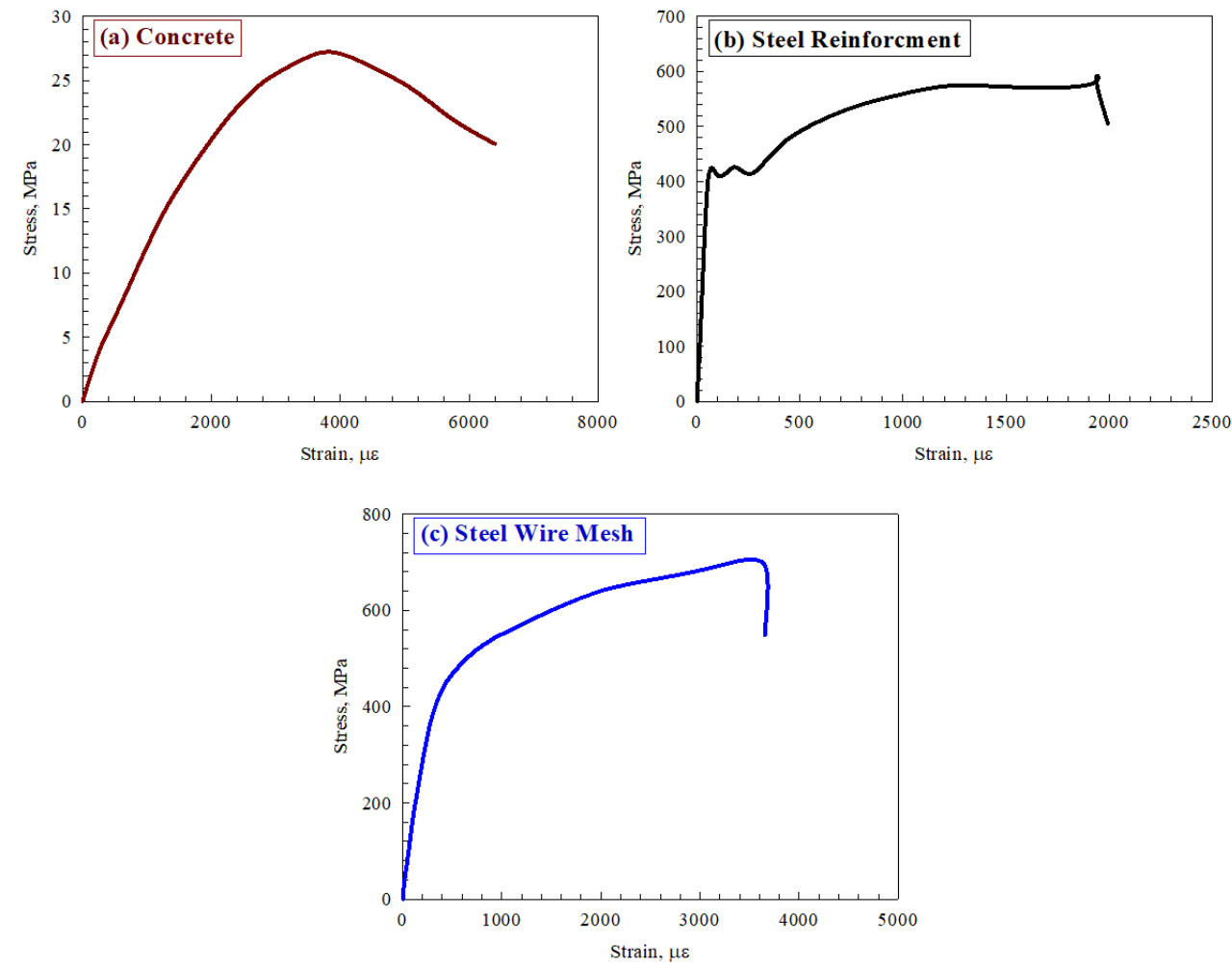

Figure 2 Stress-strain diagrams of (a) concrete, (b) steel reinforcement, and (c) steel wire mesh

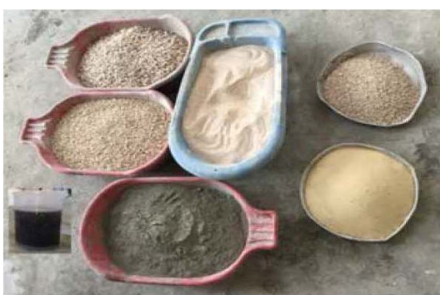

(a) Preparing the ingredients of mixture

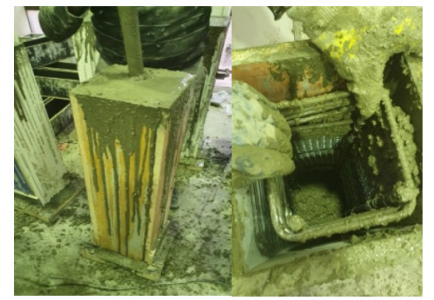

(d) Casting concrete into molds

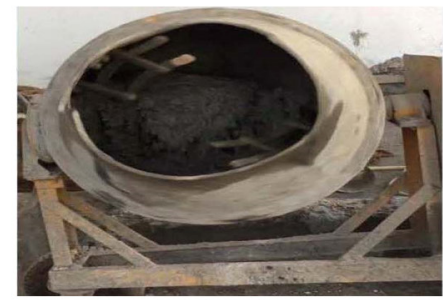

Mixing concrete by tilting drum mixer

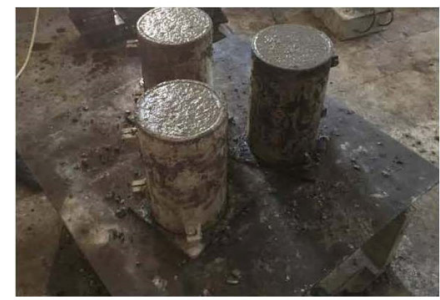

(e) Casting concrete into cylinders

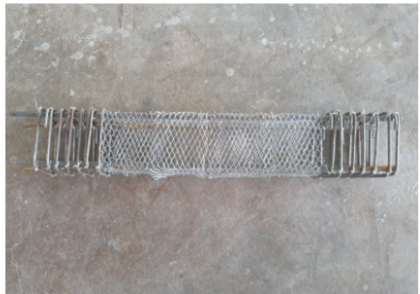

(c) Steel reinforcement

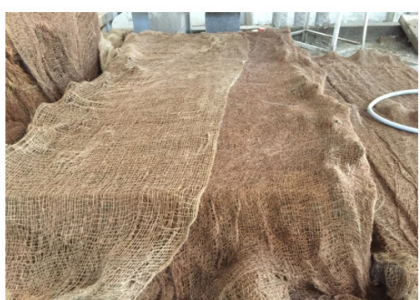

(f) Water-cured tank for 28 days

Figure 3 The mixing, casting, and curing of reinforced concrete columns

\subsection{Heat Treatment Method}

The elevated temperature was applied using an electronically-controlled electrical furnace that was able to control the temperature degree and time of exposure. Six of the column specimens were subjected to laboratory temperature (control or un-damaged specimens) of $23^{\circ} \mathrm{C}$. Eighteen of the column specimens were subjected to elevated temperatures (six columns at $250^{\circ} \mathrm{C}$, six columns at $500^{\circ} \mathrm{C}$, and six columns at $750^{\circ} \mathrm{C}$ ) for two hours. The concrete columns were confined with ASWM wraps for strengthening. Then, they are exposed to high temperatures. The furnace needed 4 hours to reach the set degree of target temperature, and then the temperature remained at that degree for two hours for damage occurrence and consequent strength reduction. To be able to, accurately examine the elevated temperature influence on the specimens' compressive and splitting tensile strengths, the residual splitting and compressive strengths were adjusted as per the control specimens. The cylinders' compressive strength at $23^{\circ} \mathrm{C}$ was $27.1 \mathrm{MPa}$, while it reduced to $23.9 \mathrm{MPa}, 19.8 \mathrm{MPa}, 15.3 \mathrm{MPa}$ for $250^{\circ} \mathrm{C}, 500^{\circ} \mathrm{C}$, and $750^{\circ} \mathrm{C}$. As 
for the splitting tensile strength, the pre-damaged cylinders' strength was $3.25 \mathrm{MPa}$, while the damaged ones were $3.05 \mathrm{MPa}$, 2.70 MPa, $2.39 \mathrm{MPa}$ for $250^{\circ} \mathrm{C}, 500^{\circ} \mathrm{C}$, and $750^{\circ} \mathrm{C}$.

\subsection{Testing Setup}

The specimens were experimented, vertically-positioned, under axial compression loading, in a specially-fabricated, rigid steel frame. The setup of testing was devised to simulate pinned-pinned conditions (spherical shape) at the two column's ends. To ensure that the load was evenly distributed, the specimens were aligned and placed using lead shims, located between the steel plates and the ends of the specimen. The load was applied using a hydraulic cylinder, having a capacity of $2000 \mathrm{kN}$. To examine the performance of the specimen's performance, beyond the peak, a monotonicapplied axial loading was increased progressively using a displacement control, at a displacement rate of $0.5 \mathrm{~mm} / \mathrm{min}$. Two LVDTs were used to monitor the average axial deformation throughout the specimen's length. The axial strains were measured using two electrical resistance strain gauges, while the lateral strain was monitored using an electrical resistance strain gauge. Further, the applied load was measured using a Load cell. Figure 1 illustrates the test setup and instrumentation.

\section{RESULTS AND DISCUSSION}

\subsection{Failure Mode}

Figure 4 depicts the modes of failure encountered by the specimens. The control columns encountered a failure in the mid-section because of the appearance of condensed stresses due to under-strengthening. At the same time, the ends were protected enough and had no before-expected failure (Figure 4 (a)).

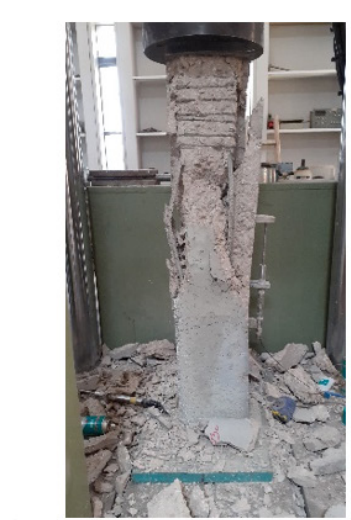

$23^{\circ} \mathrm{C}$

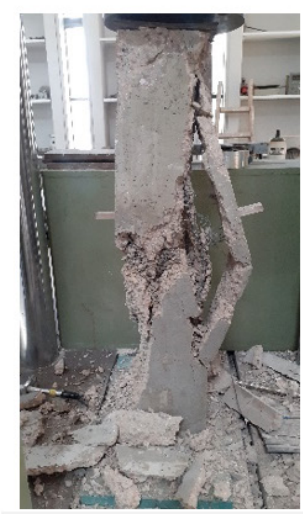

1 Layer

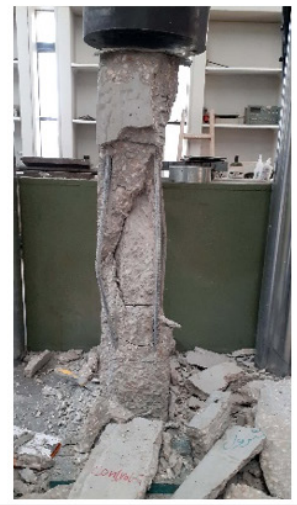

$250^{\circ} \mathrm{C}$

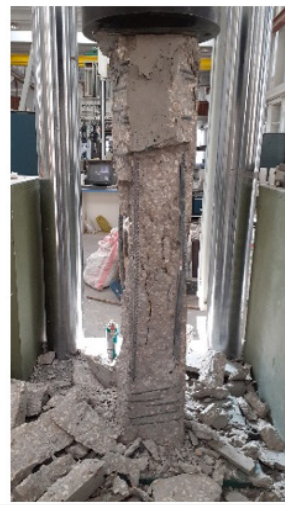

$500^{\circ} \mathrm{C}$

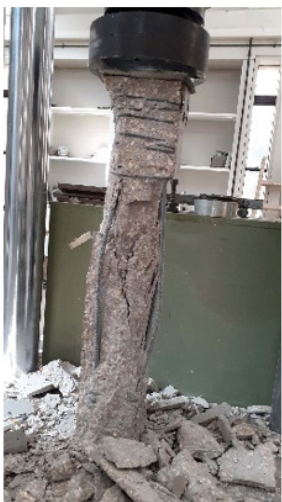

$750^{\circ} \mathrm{C}$

(a) Control column

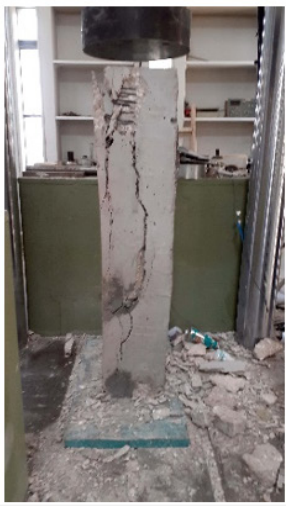

2 Layers

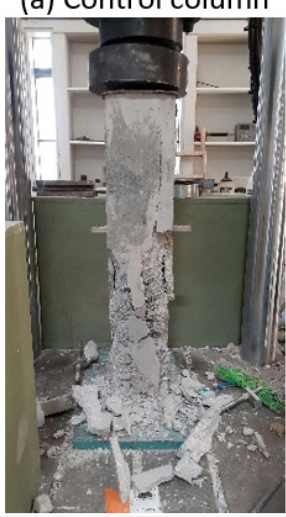

3 Layers

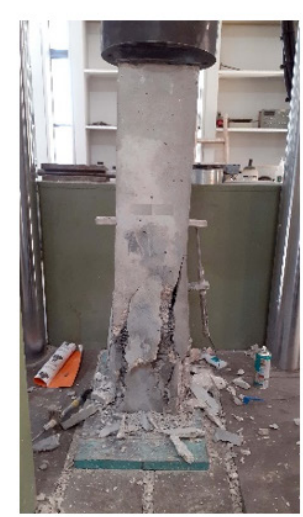

4 Layers

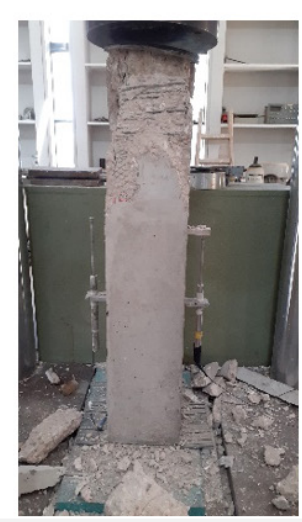

5 Layers

(b) Confined column with ASWM

Figure 4 Typical failure modes

Failure modes noted that a brittle type of failure occurred in the control specimens (without ASWM): the failure was explosively accompanied by the sudden loss of axial resistance with longi-tudinal steel reinforcement buckling. Also, the degree of damage decreased with the increase of elevated temperature, as shown in Figure 4(a). However, the heat- 
damaged specimens had a buck-ling in the longitudinal steel reinforcement, due -in part- to the degradation of the compressive strength of concrete and, in consequence, to the modulus of elasticity. It could also be referred to as the cracking of concrete caused by heat, resulting in a deficiency in the columns' cross-sectional moment of inertia. In addition, the steel rebar reinforcement of the heat-damaged specimens en-countered a degradation, inevitably, in the tensile strength and the steel rebar-concrete bond strength, which contributed to the reduction of the specimens' axial compressive strength (Figure 4 (a)). The specimen's failure typically occurred in the form of a fracture in the ASWM, at/close to the center region of the specimen except the specimens confined with four and five layers in which the failure occurred at the ends. This means that the four layers are enough to transfer the failure from the core to the ends. Confined-with-ASWM specimens failed at the ends while the main core stayed intact because the core was strengthened with the ASWM wraps, unlike the ends (Figure 4 (b)). While the loading was at its early and middle steps, some sounds were heard, indicating cracking in the micro-levels' wrapped core. When the loading was more raised, approaching the peak level, the surrounding ASWM broke, which released energy abruptly, and produced a big noise. As the ASWM began to fail, the specimen's resistance degraded. Upon failure, the concrete broke down into scat-tered pieces, and a very noise was produced; then, the longitudinal reinforcement buckled. Similar-ly, the control specimens' concrete crushed, buckling of longitudinal reinforcement followed, leading to failure.
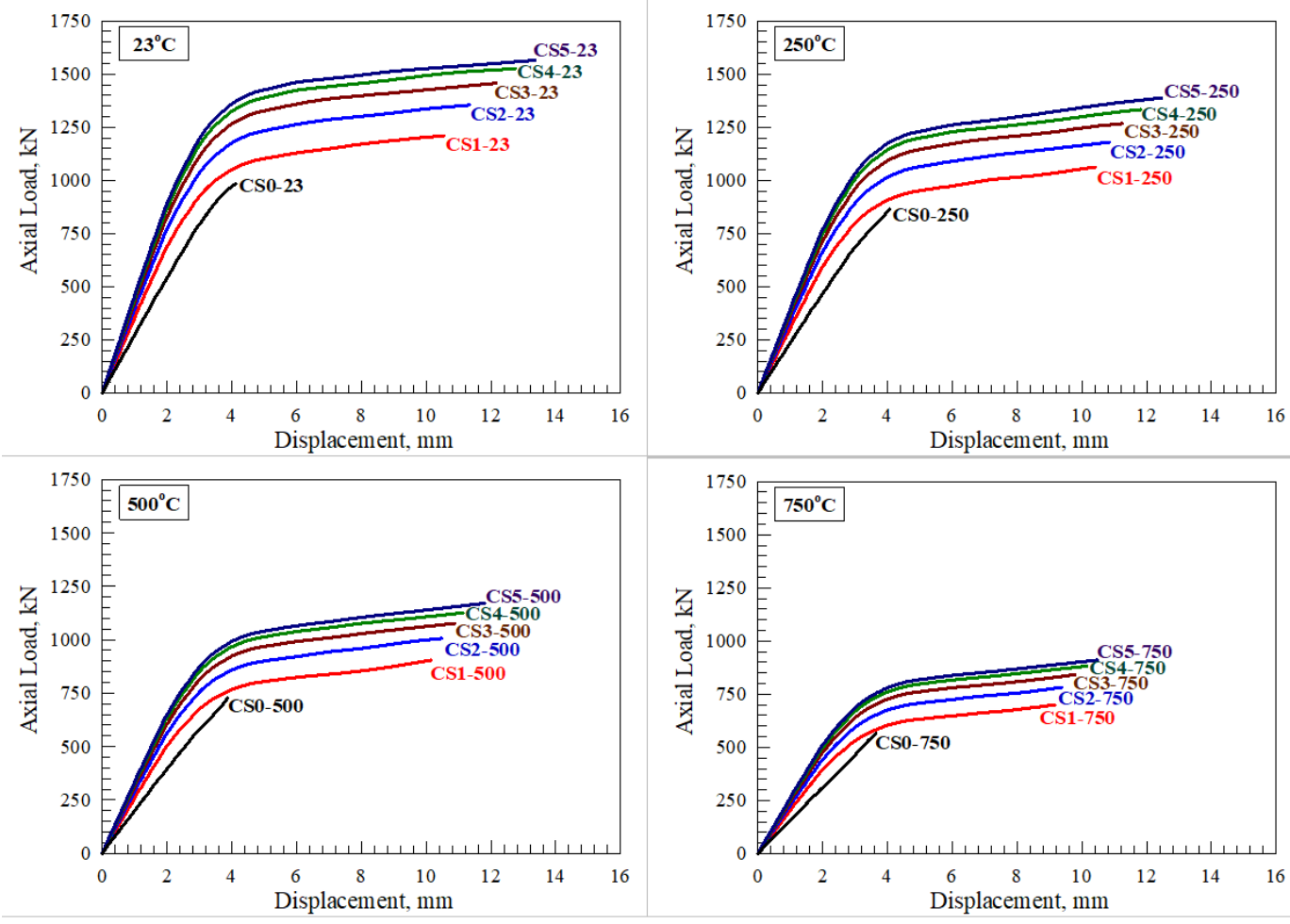

Figure 5 Axial load versus axial displacement curves

\subsection{Loading Behavior Stages}

Figure 5 illustrates the specimens' curves of axial load versus axial displacement and axial loads versus lateral strain. The axial load versus axial displacement curve consisted of two parts: the pre-cracking, represented by a straight slope, while the second part represented the post-cracking stage, with a slope variation. The axial load carrying capacity was higher in the confined-withASWM specimens than the control columns, regardless of being damaged or not. In addition, increasing the layers of ASWM improved the confined specimen's axial load and corresponding displacement, in addition to stiffness, unlike the control specimens. These improvements were more pronounced, although not proportional, when the number of ASWM was increased. The confined specimens' loading behavior had three phases: Phase 1 extends from zero loads to $0.65 \mathrm{~N}_{\mathrm{p}}$ (peak load, Figure 6), where all the specimens' behavior was near linear (Figure 5). In this phase, the axial displacement of the un-damaged confined specimens was $20 \%$. Also, for the elevated temperature ones was $21 \%$ of the ultimate displacement, as illustrated in Figure 5. Phase 2 extends from $0.65 \mathrm{~N}_{\mathrm{p}}$ to $0.8 \mathrm{~N}_{\mathrm{p}}$, representing the steel-yielding phase, where the concrete was at its peak strain and began to expand, largely; further, the ASWM wraps started to crush, due to stresses, at the end of this phase. Phase 3 occurred when 
the load exceeded $0.8 \mathrm{~N}_{p}$, big deformation appeared, axially and laterally, and a slight increase in load. Post concrete crushing, the ASWM carried the load till breaking.

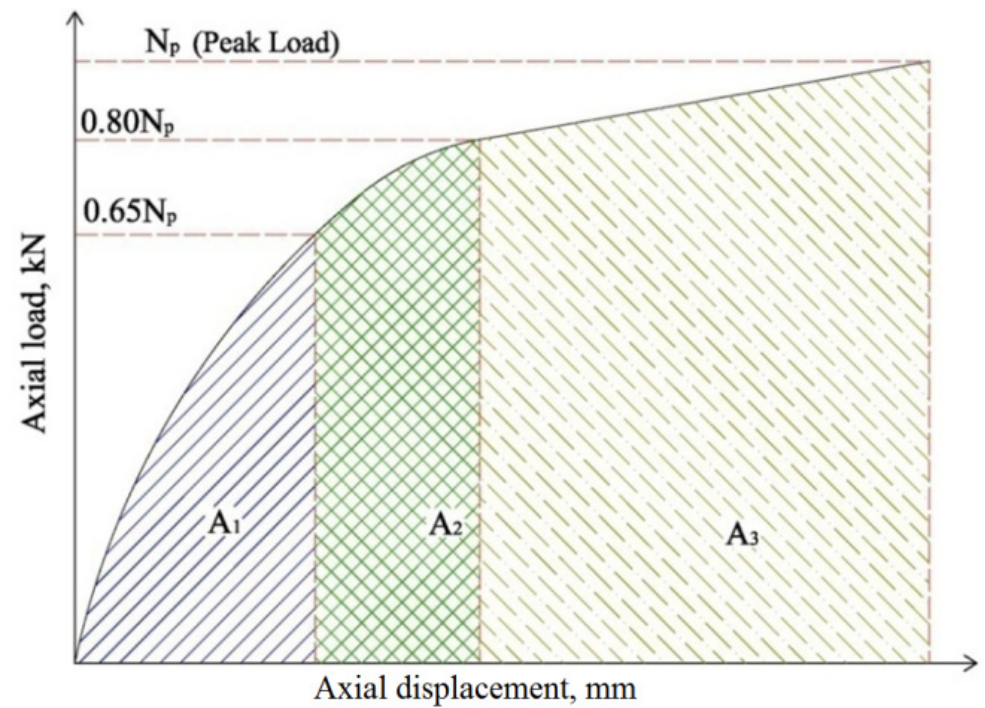

Figure 6 Typical loading behavior stages of the tested columns

To better understand these phases' influence, energy absorption (EA) was determined by calculating the area beneath the load-displacement curve until the point of ultimate capacity. To be able to determine the amount of energy absorption during each phase, the area underneath the axial load versus axial displacement curve was split into three parts (Figure 7): $A_{1}$ ) covers the area of phase $A$, from zero to $0.65 N_{p} ; A_{2}$ ) covers the area of phase $B$, from $0.65 N_{p}$ to $0.80 \mathrm{~N}_{\mathrm{p}}$, and $\mathrm{A}_{3}$ ) the area under phase $\mathrm{C}$, from $0.80 \mathrm{~N}_{\mathrm{p}}$ to peak $\mathrm{N}_{\mathrm{p}}$. Figure 7 depicts the modified values of energy absorption, for the whole areas, as per the total columns' energy absorption. Figure 7 shows that the ASWM fibers, in phase $C$, absorbed $80-85 \%$ of the total energy after the concrete had crushed until the breakage of fibers. In phases A and $B$, the energy absorption rate was almost similar, reaching to $15-20 \%$ of the total energy; this ratio increased when more layers of ASWM were added (Figure 7(a)). However, in phase $C$, the damaged confined columns began to decrease EA (Figure 7 (b)). In addition, Figure 7 (b) depicted that the elevated temperature decreased the EA percentages by $20 \%$, $37 \%$, and $58 \%$ for $250^{\circ} \mathrm{C}, 500^{\circ} \mathrm{C}$, and $750^{\circ} \mathrm{C}$.
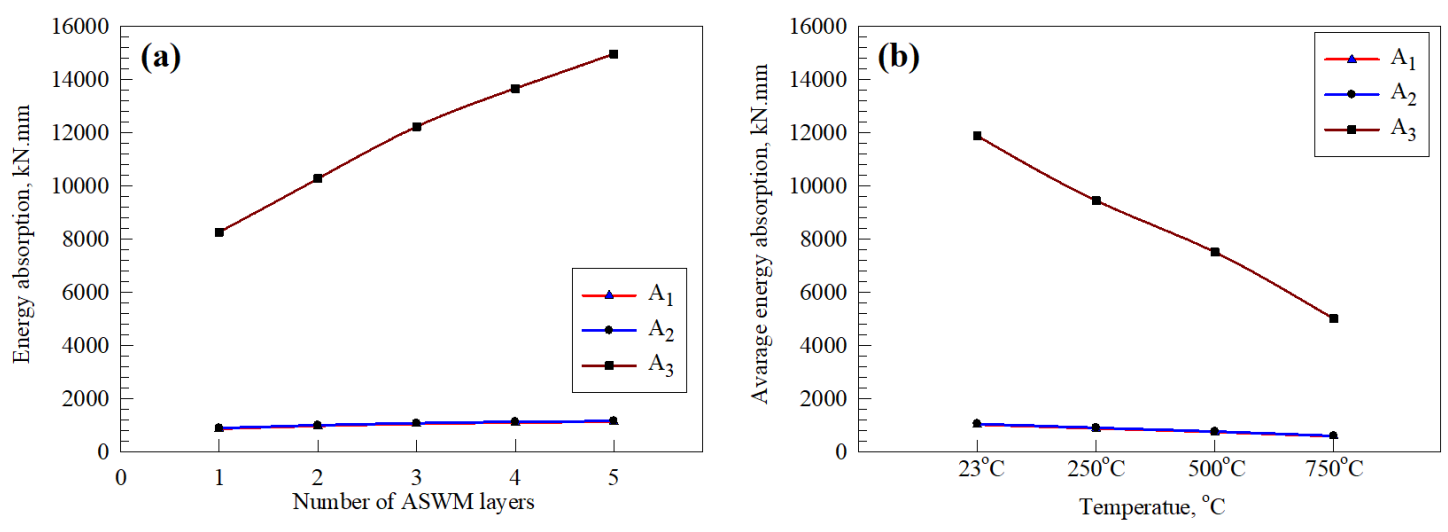

Figure 7 Energy absorption at different stages versus (a) number of ASWM layers and (b) temperature

\subsection{Axial and Lateral Strain}

Figure 8 illustrates the axial load versus axial and lateral strain curves for the specimens. The curves indicated that the ASWM were stressed once the specimens' axial capacity was higher than the control columns' (the concrete and primary steel bar reinforcement contributing to axial load capacity). In phase A (pre-cracking), the lateral strains were determined by sight for both groups of columns, un-damaged (Figure 8(a)) and damaged (Figure 8(b)); while the strain of ASWM reached $20 \%$ (of the peak strain) for the un-damaged columns, and $21 \%$ for the damaged ones. It was noted that the concrete conveyed the load. In phase B, the axial strain in the un-damaged specimens was $12 \%$, while the 
damaged ones were $8 \%$. These values are assumed to be in between the pre-cracking and cracking phases, in which the concrete carried the load, along with the streel. As for phase C, the ASWM strain in the un-damaged columns was $68 \%$ of the peak level, while the dam-aged columns had $71 \%$. It was found that these percentages sharply increased when the load was slightly incremented. By that, the columns were presumed to be in the post-cracking stage. It is worth mentioning that the sharp increase in the ASWM's strain rate, corresponding to a slight in-crement of load, was to the loss of resistance provided by concrete due to the emergence and propa-gation of cracks. In addition to the loss of resistance availed by the prime steel reinforcement due to buckling, leading to a big reduction in the overall resistance since the resistance was availed, only by the ASWM. Maximum levels of stresses condensed, evidently, at the column's middle height (Figure 4(a)), indicating that the ASWM material must be erected extensively at that region to get the best results. The measured values of lateral and axial failure strains were $7400 \mu \varepsilon$ and $3600 \mu \varepsilon$, re-spectively, indicating that the columns' concrete failed at a much less strain capacity than the ASWM's ultimate strain capacity. The occurrence of failure affirmed this without rupturing the ASWM.
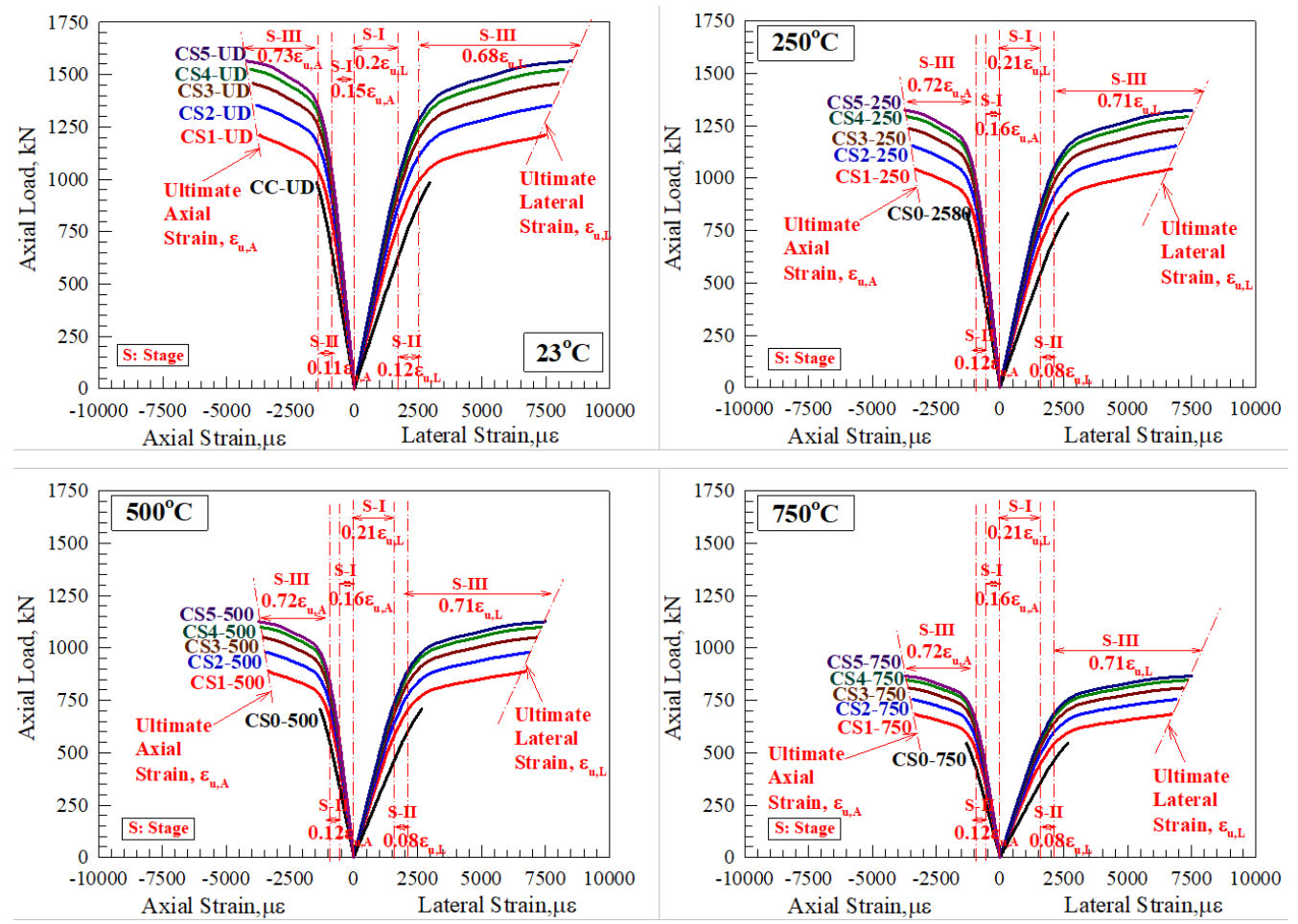

Figure 8 Axial load versus axial and lateral strain curves

\subsection{Failure Loads}

Figure 9 illustrates the ASWM's ultimate failure load percentages with respect to the control undamaged column (CSO-23). Figure 9 reveals that the elevated temperature of $250^{\circ} \mathrm{C}, 500^{\circ} \mathrm{C}$, and $750^{\circ} \mathrm{C}$ caused a reduction in ultimate failure load of $12 \%, 26 \%$, and $43 \%$, respectively. In the un-damaged specimens, the number of ASWM layers had, notably, impacted the ASWM efficiency, with percentages (as per the un-damaged control column's ultimate strength) of 23\%, $38 \%, 48 \%, 55 \%$, and 59\% for one, two, three, four, and five ASWM layers, respectively. On the other side, the percentages of damaged columns' strength at a temperature of $250^{\circ} \mathrm{C}$ (as per the ultimate strength of ASWM) were $8 \%, 20 \%, 29 \%$, $35 \%$, and $41 \%$ for one, two, three, four, and five ASWM layers, respectively. This reflects that the one to five layers of ASWM effectively regains the un-damaged column's capacity at a temperature of $250^{\circ} \mathrm{C}$. In addition, the percentages of damaged columns' strength at a temperature of $500^{\circ} \mathrm{C}$ (as per the ultimate strength of ASWM) were $-8 \%, 2 \%, 9 \%, 14 \%$, and $19 \%$ for one, two, three, four, and five ASWM layers, respectively. This reflects that the two to five layers of ASWM effectively regain the capacity of the un-damaged column at a temperature of $500^{\circ} \mathrm{C}$. On the other hand, the one layer of ASWM is not practical to recover the strength un-damaged column. While, the percentages of damaged columns' strength at a temperature of $750^{\circ} \mathrm{C}$ (as per the ultimate strength of ASWM) were $-29 \%,-21 \%,-14 \%,-10 \%$, and $-8 \%$ for one, two, three, four, and five ASWM layers, respectively. This reflects that the one to five layers of ASWM is not effective in recovering the strength un-damaged column at a temperature of $750^{\circ} \mathrm{C}$. It can be concluded, from the obtained results, that the technique of internally-reinforcing with ASWM wraps has proven to be highly more efficient at a temperature 
of $23^{\circ} \mathrm{C}, 250^{\circ} \mathrm{C}$, and $500^{\circ} \mathrm{C}$ in enhancing the RC columns' axial strength. Also, ASWM slowed down the cracks' growth rate in the column's middle height by bridging those cracks and carrying stresses across them, which raised the crack resistance and delayed steel buckling. As a result, the RC columns' performance improved, under service load conditions, due to the enhancements in each of ultimate axial load, elastic stiffness (Table 2), and EA (Table 2). Finally, the ultimate load's enhancement percentages (Table 2) were determined as per the control column, as in Figure 9. It was noticed that the strength gain rate reduced when the ASWM layers increased, but up to four layers only; as no significant changes were noticed when erecting more than four layers, in each of ductility behavior (Figure 5) and ultimate load (Figure 9). In contrast, the stiffness kept on rising (Table 2). The stiffness enhancement (Table 2) reduced the lateral expansions of ASWM stresses (Figure 8), delayed the steel yielding, and enhanced the concrete crushing load.

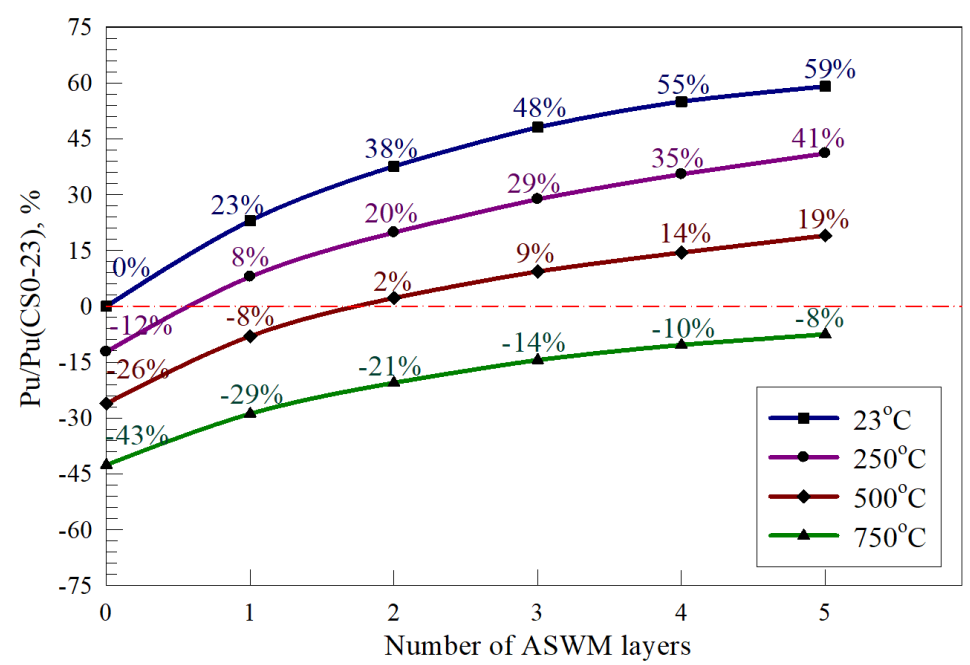

Figure 9 Failure load percentage with respect to control undamaged column (CSO-23)

\subsection{Column Ductility}

Ductility is the structure's ability to endure inelastic deformations without negatively affecting the load-carrying capacity. As for RC columns, ductility is crucial because of their failure mode, which is brittle. The ASWM's EA and ductility are depicted in Figure 10. Reviewing Figure 10, it was found increasing the ASWM layers enhanced the ductility. It was also found that ductility improved when the elevated temperature increased. This indicated that the un-damaged columns had less ductility than damaged ones. Whereas the ductility behavior of the columns at $23^{\circ} \mathrm{C}, 250^{\circ} \mathrm{C}, 500^{\circ} \mathrm{C}$, and $750^{\circ} \mathrm{C}$ reduced with erecting five and four layers of ASWM sheets, respectively. Where these numbers of layers were the adequate configurations to provide better ductility. Whereas the ductility behavior (Stabilization of the ductility) of the columns at $23^{\circ} \mathrm{C}, 250^{\circ} \mathrm{C}, 500^{\circ} \mathrm{C}$, and $750^{\circ} \mathrm{C}$ decreased after two, three, four, and five layers of ASWM, respectively. Which can be classified as the maximum amount for adequate ductility.

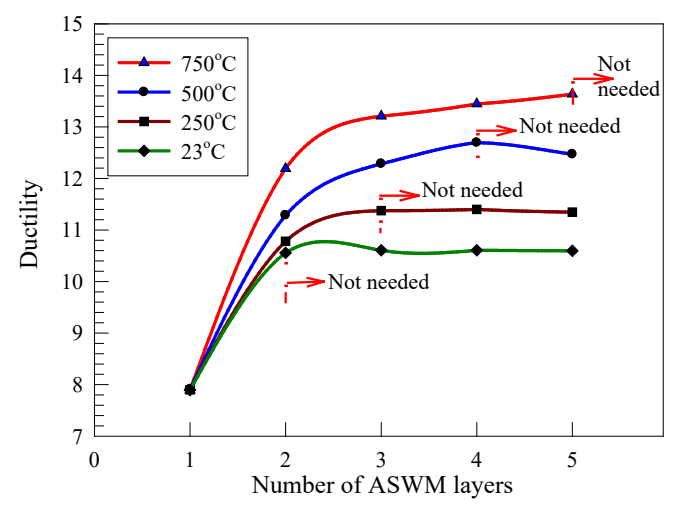

Figure 10 Ductility versus number of ASWM layers 

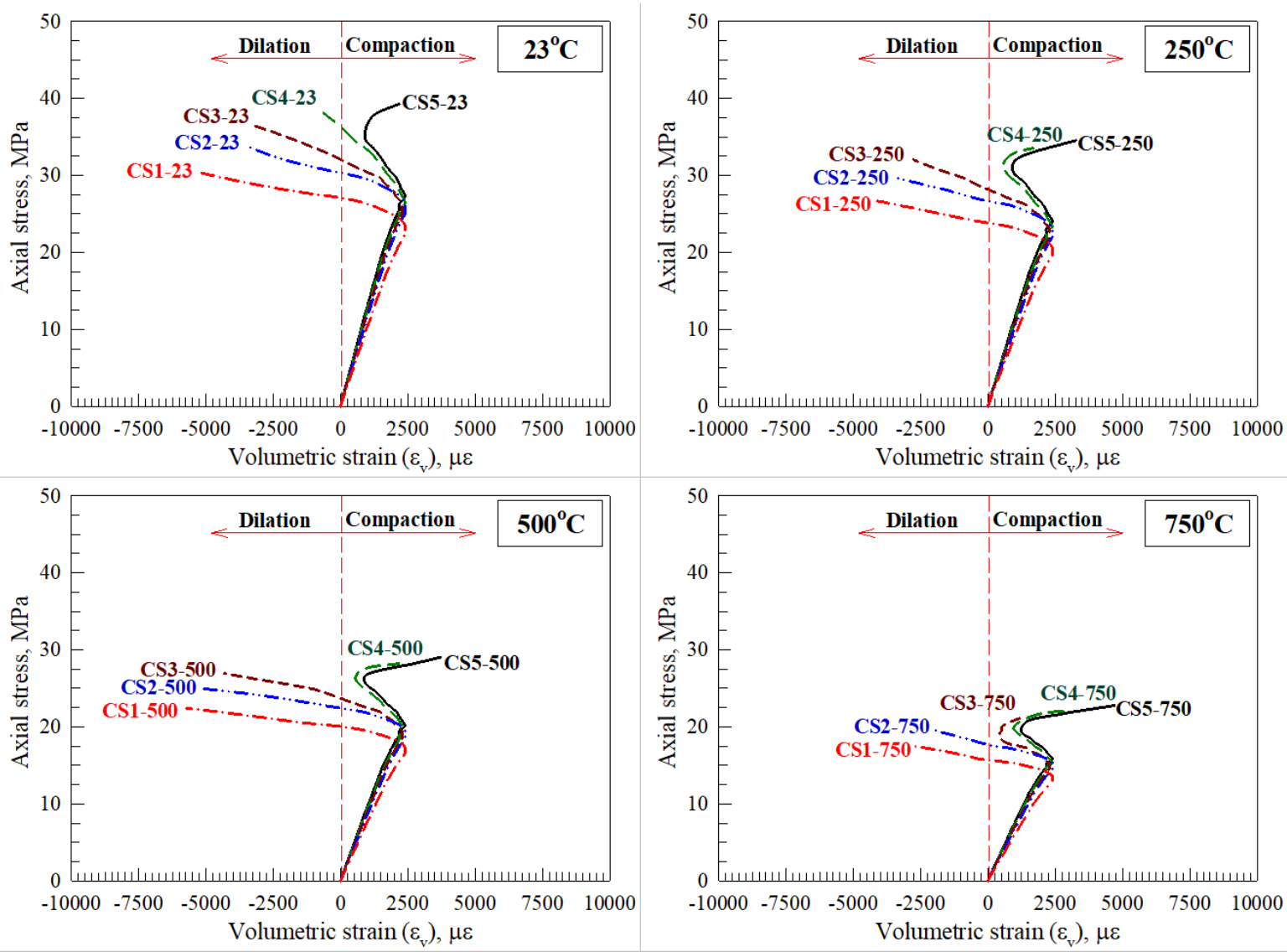

Figure 11 Volumetric strains for tested columns

\subsection{Dilation Properties}

The volumetric strain is the ratio of the change in the column's volume to the column's deformation to its original volume. It can be determined by summing up the axial strain and lateral strains. Figure 11 shows the average volumetric strain curves versus the axial stress for columns wrapped with ASWM. Inspecting Figure 11(a) showed that, in the undamaged columns $\left(23^{\circ} \mathrm{C}\right)$, one to four layers of ASWM failed to avail a confinement pressure enough to withstand the concrete's dilation tendency, while five layers reversed the concrete's dilation trend (Compaction). In the damaged columns at $250^{\circ} \mathrm{C}$ and $500^{\circ} \mathrm{C}$, one to three ASWM layers did not give a confinement pressure enough to resist the concrete's dilation tendency; however, four to five layers were sufficient to reverse the concrete's dilation trend (Compaction). At $750^{\circ} \mathrm{C}$, one to two ASWM layers did not give a confinement pressure enough to resist the concrete's dilation tendency; however, three to five layers were sufficient to reverse the concrete's dilation trend (Compaction). Thus, it is established that four ASWM layers, minimum, are enough to provide efficient confinement to damaged columns at $250^{\circ} \mathrm{C}$ and $500^{\circ} \mathrm{C}$; whereas, the damaged columns at $750^{\circ} \mathrm{C}$ need at least three layers of ASWM. It can be concluded that the reduction in the compressive strength of damaged concrete enhanced the required number of ASWM layers to give proper resistance to the concrete's dilation.

\subsection{Amount of ASWM for Sufficient Confinement and Ductility}

The columns' average compressive strength before being elevated temperature was $27.1 \mathrm{MPa}$, and it was $23.9 \mathrm{MPa}$, 19.8 MPa, $15.3 \mathrm{MPa}$ after being exposed to $250^{\circ} \mathrm{C}, 500^{\circ} \mathrm{C}$, and $750^{\circ} \mathrm{C}$, respectively, as shown in Figure 12 . Figure 12 exhibits the required number of ASWM layers to avail adequate ductility and confinement against concrete compressive strength. Based on the dilation properties and column ductility shown in Figure 12, the maximum and minimum layers of ASWM were five and three, respectively, for damaged columns at $750^{\circ} \mathrm{C}$ or with concrete compressive strength less than 19.8 MPa. Also, Figure 12 showed that four ASWM layers and concrete compressive strength of $19.8 \mathrm{MPa}$ are the optimum values required to achieve proper ductility and confinement properties. The columns had a concrete compressive strength of more than $19.8 \mathrm{MPa}$. The behavior was affected by concrete compressive strength, reflecting that certain ASWM layers need to provide ductility and confinement properties adequately. 


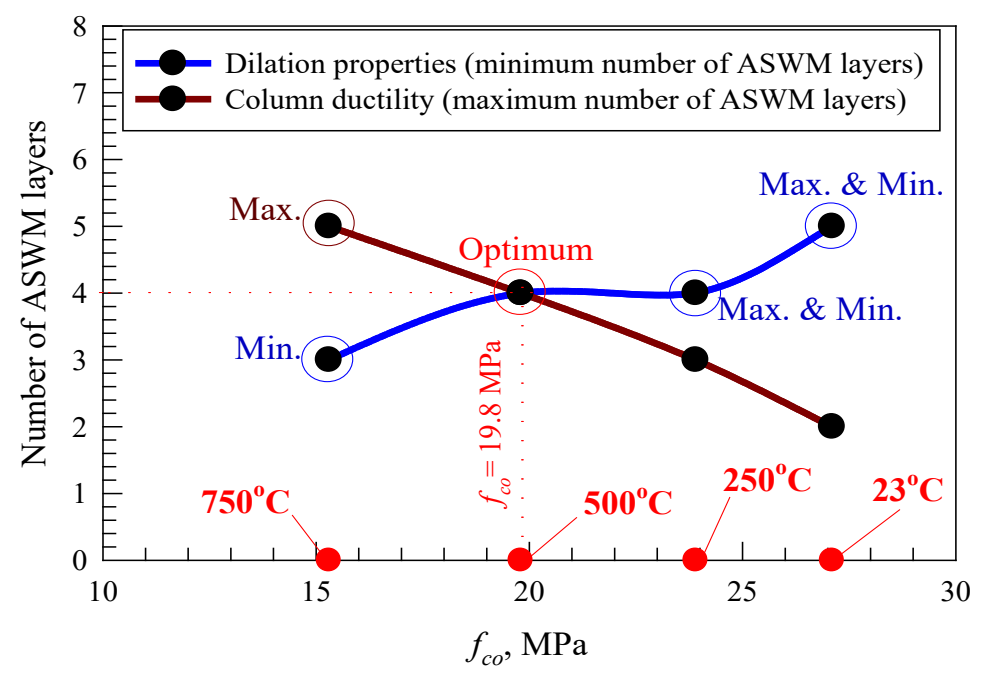

Figure 12 Number of ASWM layers versus unconfined strength of concrete

\subsection{Profitability Index and Confinement Effectiveness of the ASWM Number}

The ASWM's contribution to the axial strength was evaluated by finding the difference between the control's strength and the confined columns' strength. This means of evaluation is satisfactory, as the specimens had the same fabrication, reinforcement, and testing circumstances. The profitability indices had been computed to assess the number of ASWM layers' effectiveness in terms of the consumed amount of ASWM. The profitability index is the ratio of ASWM contribution in axial capacity to the total ASWM area. Figure 13 illustrates the profitability indices of different numbers of layers. Inspecting Figure 13 revealed that the profitability index became lower due to elevated temperature or increased ASWM layers. The increase in the number of ASWM layers resulted in a reduction in the profitability index; hence, slowing down the fracturing of ASWM and consequently enhancing the ultimate load at failure. In addition, the maximum and minimum layers of ASWM were four and five for columns exposed to $250^{\circ} \mathrm{C}$ and $23^{\circ} \mathrm{C}$, respectively, or with concrete compressive strength more than $19.8 \mathrm{MPa}$. These results provided an evaluation criterion of efficient use of ASWM, as an internal lateral reinforcement system, in terms of the consumed amount of ASWM. The method of internal ASWM is useful, particularly in the thermally-shocked columns.

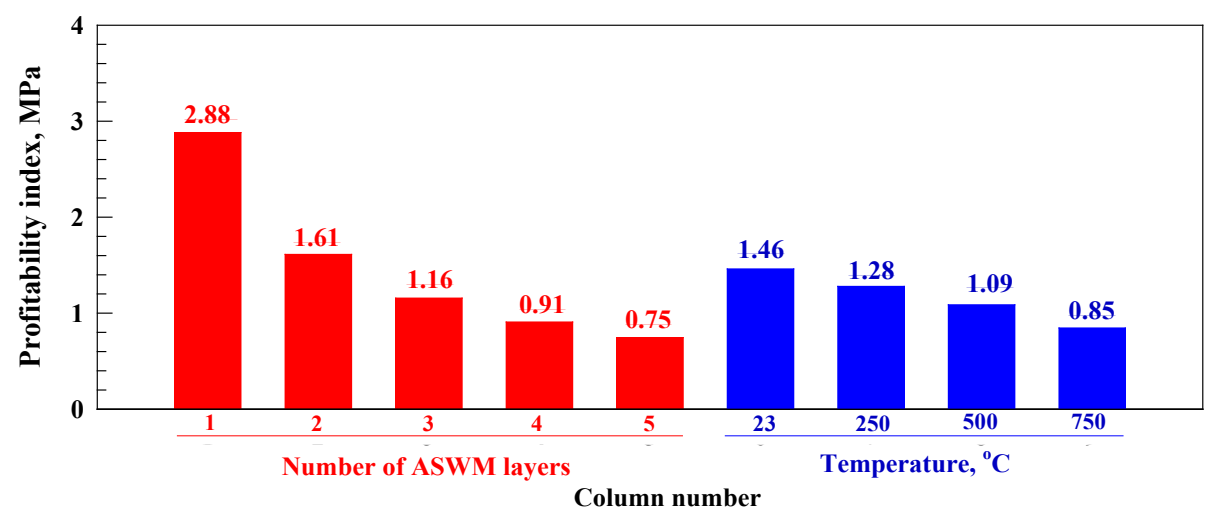

Figure 13 Profitability index

\section{CONCLUSION}

Based on the results and observations, the following conclusions are drawn:

1. This study showed that elevated temperatures degraded the experimented RC columns' axial load resistance in pure compression. The very high temperatures reduced the specimens' axial stiffness but enhanced their toughness, ductility, and deformation capacity. It was also observed that the longer the time of exposure to extremely high temperatures, the more influenced the performance of the column.

2. The ASWM confinement method considerably improved the heat-damaged specimens' ductility, toughness, and axial resistance. This method played a crucial role in improving, to a significant extent, the axial strength of the 
columns that had lower unconfined compressive strength and exposed, heavily, to heat. This study showed that an adequate level of lateral confinement with ASWM helped the heat-damaged specimens restore their original strength, but not the axial stiffness.

3. ASWM jacket enhanced the strength, stiffness, and toughness while it reduced their ductility.

4. Confining the heat-damaged RC columns with ASWM resulted in an enhancement in the columns' deformation capacity and further improved their toughness.

5. The reinforced-with-ASWM column specimens exhibited an enhancement in their deformation capacity and ultimate failure load, indicating an enhancement in the specimens' ductility. This technique of reinforcement is viable to use in earthquake-resistant structures.

6. The use of the circularizing technique in this study ensured evenly-distributed confining stresses all around the column's section circumference and enhanced the effectiveness of the ASWM wrapping

7. In the confined-with-ASWM columns, the axial load versus axial displacement curve has three stages: Stage A: less expansion of concrete and less constraining effect of ASWM; stage B: starts with a significant expansion of concrete, passing through the stressing of ASWM, and ends with concrete crushing; and stage $\mathrm{C}$ : in which the load is conveyed by the ASWM material, after concrete crushing, until the breakage of ASWM.

8. The confined columns' mode of failure was explosive, having: concrete crushing at column ends, abrupt degradation of axial resistance, the breakage of the lateral reinforcement, and the buckling of the longitudinal reinforcement. As for the columns without confinement, the failure mode was unexpected, and it took place at the column's midheight section; then, the longitudinal reinforcement buckled.

9. The number of ASWM layers enhanced, to a great extent, the percentages of ductility, energy absorption, and ultimate load. When the layers of ASWM exceeded a specific number, both the column's ductility and ultimate load stayed almost unchanged, whereas the stiffness kept on increasing significantly.

\section{Acknowledgement}

This work was fully supported by a grant from the Deanship of Research at Jordan University of Sci-ence and Technology (Project No. 2020/122). This support is gratefully acknowledged.

Editor: Marcílio Alves

\section{References}

Abdalla, K.M., Al-Rousan, R.Z., Alhassan, M.A., Lagaros, N.D. (2019) Modeling and analysis of optimized rectangular RC columns confined with CFRP composites. Jordan Journal of Civil Engineering; 13(2): 325-334.

Adam JM, Ivorra S, Pallares FJ, Gimenez E, Calderon PA. (2009) Axially loaded RC columns strengthened by steel caging. Finite element modelling. Construction and Building Materials; 23(6): 2265-7226.

Al-Rousan, R.Z., AL-Tahat, M.F. (2020) Consequence of anchoring holes technique on the bond behavior between CFRP composites and heat-damaged concrete. Structures; 27: 1903-1918.

Al-Rousan, R.Z., Barfed, M.H. (2019) Impact of curvature type on the behavior of slender reinforced concrete rec-tangular column confined with CFRP composite. Composites Part B: Engineering; 173: 106939.

Al-Rousan, R.Z., Issa, M.A. (2018) Stress-strain model and design guidelines for CFRP-confined circular reinforced concrete columns. Polymer Composites; 39(8): 2722-2733.

Anawat Thipprasert, Chinnapat Buachart, Chayanon Hansapinyo, Suchart Limkatanyu. (2019) Seismic Upgrading of Exterior Reinforced Concrete Frame with Small Column and Joint Area Using Externally Attached Steel Column. Latin American Journal of Solids and Structures; 16(6): 1-17.

Arioz O. (2007) Effects of elevated temperatures on properties of concrete. Fire Safety Journal; 42(8): 516-522

Badalamenti V, Campione G, Mangiavillano ML. (2010) Simplified model for compressive behavior of concrete col-umns strengthened by steel angles and strips. Journal of Engineering Mechanics; 136(2): 230-238. 
Chiang CH, Tsai CL. (2003) Time-temperature analysis of bond strength of a rebar after fire exposure. Cement and Concrete Research; 33(10): 1651-1654

Ebrahim Zamani Beydokhti, Hashem Shariatmadar. (2016) Behavior of Damaged Exterior RC Beamâ-Column Joints Strengthened by CFRP Composites. Latin American Journal of Solids and Structures; 13(5): 880-896.

Fletcher IA, Welch S, Torero JL, Carvel RO, Usmani A. (2007) Behavior of concrete structures in fire. Thermal Sci-ence; 11(2): $37-52$

Frangou M, Pilakoutas K, Dritsas S. (1995) Structural repair strengthening of RC columns. Construction and Building Materials; 9(5): 259-266.

Garzon-Roca J, Adam JM. (2011) Behaviour of RC columns strengthened by steel caging under combined bending and axial loads. Construction and Building Materials; 25(5): 2402-2412.

Georgali B, Tsakiridis PE. (2005) Microstructure of fire-damaged concrete. A case study. Cement and Concrete Com-posites; 27(2): 255-259

Gimenez E, Adam JM, Ivorra S, Calderon PA. (2009) Influence of strips configuration on the behaviour of axially loaded RC columns strengthened by steel angles and strips. Materials and Design; 30(10): 4103-4111.

Hertz KD. (2005) Concrete strength for fire safety design. Magazine of Concrete Research; 57(8): 445-453

Issa, M.A., Alrousan, R.Z., Issa, M.A. (2009) Experimental and parametric study of circular short columns confined with CFRP composites. Journal of Composites for Construction; 13(2): 135-147.

Iyappan. G.R, Dr. D. Elango. (2017) Strengthening of RC Square Column using Stainless Steel Wire Mesh. Interna-tional Journal of Constructive Research in Civil Engineering (IJCRCE); 3(3): 16-23.

Janotka I, Nurnbergerova T. (2005) Effect of temperature on structural quality of the cement paste and high-strength concrete with silica fume. Nuclear Engineering and Design; 235(17-19): 2019-2032

Khoury GA, Majorana CE, Pesavento F, Schrefler BA. (2002) Modelling of heated concrete. Magazine of Concrete Research; 54(2): 77-101

Lambert-Aikhionbare N, Tabsh SW. (2001) Confinement of high-strength concrete with welded wire reinforcement. ACl Structural Journal; 98(5): 677-685.

Luccioni BM, Figueroa MI, Danesi RF. (2003) Thermo-mechanic model for concrete exposed to elevated tempera-tures. Engineering structures; 25(6): 729-742

Moghaddam H, Samadi M, Pilakoutas K, Mohebbi S. (2010) Axial compressive behavior of concrete actively confined by metal strips; Part A: experimental study. Materials and Structures; 43(1): 1369-1381.

Netinger I, Kesegic I, Guljas. (2011) The effect of high temperatures on the mechanical properties of concrete made with different types of aggregates. Fire Safety Journal; 46(7): 425-430

Neves IC, Rodrigues JPC, Loureiro AP. (1996) Mechanical properties of reinforcing and prestressing steels after heating. Journal of Materials in Civil Engineering; 8(4): 189-194

Ozcan O, Binici B, Ozcebe G. (2008) Improving seismic performance of deficient reinforced concrete columns using carbon fiber-reinforced polymers. Engineering structures; 30(6): 1632-1646

Parvin A., Wang W. (2005) Behavior of FRP jacketed concrete columns under eccentric loading. Journal of Composite Construction; 5(3): 146-152

Priestley MJN, Seible F, Xiao Y, Verma R. (1994) Steel jacket retrofitting of reinforced concrete bridge columns for enhanced shear Strength-Part 2: test results and comparison with theory. ACI Structural Journal; 91(5): 537-551.

Rajai Z. Al-Rousan. (2020) Behavior of CFRP strengthened columns damaged by thermal shock. Magazine of Civil Engineering; 97(5): 9708

Ramirez JL, Barcena JM, Urreta JI, Sanchez JA. (1997) Efficiency of short steel jackets for strengthening square sec-tion concrete columns. Construction and Building Materials; 11(5-6): 345-352.

Saleh Yhya Laseima, A. A. Mutalib, S. A. Osman, N. H. Hamid. (2020) Seismic Behavior of Exterior RC Beam-Column Joints Retrofitted Using CFRP Sheets. Latin American Journal of Solids and Structures; 17(5): 1-21. 
Sezen H, Miller EA. (2011) Experimental evaluation of axial behavior of strengthened circular reinforced-concrete columns. Journal of Bridge Engineering; 16(2): 238-247.

Sim JI, Yang KH. (2009) Flexural behavior of reinforced concrete columns strengthened with wire rope and T-plate units. ACI Structural Journal; 106(5): 697-705.

Tugrul Bolukbas, Osman Hamdi Mete. (2020) A Buckling Behavior of Elliptic Perforated Steel CHS Columns Exposed to Axial Compression Load. Latin American Journal of Solids and Structures; 17(4): 1-22

Xiao Y, Wu H. (2003) Retrofit of reinforced concrete columns using partially stiffened steel jackets. Journal of Struc-tural Engineering; 129(6): 725-32.

Yang KH, Ashour AF, Lee ET. (2009) Axial behaviour of reinforced concrete short columns strengthened with wire rope and Tshaped steel plate units. Magazine of Concrete Research; 61(2): 143-154.

Yang KH, Ashour AF. (2007) Tests of reinforced concrete short columns laterally strengthened with wire rope units and steel elements. Magazine of Concrete Research; 59(8): 547-557.

Yang KH. (2012) Flexural behaviour of RC columns using wire ropes as lateral reinforcement. Magazine of Concrete Research; 64(3): 269-281. 